\title{
What Should Public Health Nurses Do in the Preparedness Phase of Disaster?
}

\author{
Ardia Putra D, Hajjul KamiliD, Yuswardi Yuswardi*iD, Elly Wardani(D) \\ Department of Nursing Management, Faculty of Nursing, Universitas Syiah Kuala, Banda Aceh, Indonesia
}

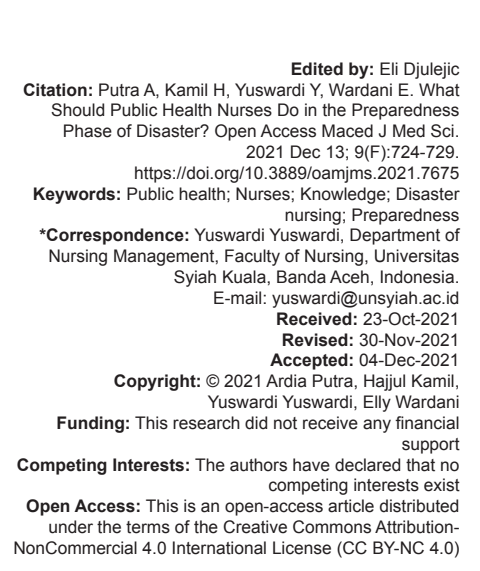

\section{Abstract}

Disasters will lead to various problems in the community that cannot be resolved through standard procedures and require the assistance of other resources. Natural and human-caused disasters have been and will continue to occur throughout the world. This event strongly encouraged the nursing profession to develop a strategic plan to address the situation, which challenges the Public Health Nurses (PHNs) to handle catastrophic situations. The goal of the study was to explore the perceived knowledge and skills of PHNs in disaster management. A systematic review approach was applied; sources of information derived from the literature were obtained through various methods. In this study, the knowledge and skills of the PHNs in disaster management are discussed at the disaster preparedness stage (disaster risk and population identification, including inter-agency collaboration). PHNs should always be aware and ready for the future disaster occurrences by enhancing their knowledge and heightening their clinical practice skills, particularly in disaster management. In addition, the collaboration among the health department and other institutions is required to develop regular disaster drills between health-care providers and communities to enhance self-awareness and preparedness regarding emergency and disaster events.

\section{Introduction}

Disaster can be defined as an ecological disturbance or an emergency event with severity and magnitude that results in death, injury, illness, human suffering, economic and social disruption [1], damage to community property, disruption of community functions, and the need for the assistance of external resources to maintain essential services [2]. In addition, disasters also produce many problems throughout the community that cannot be solved using regular procedures and require assistance from other resources [3].

The biggest earthquake and Tsunami in late 2004 in Aceh and parts of North Sumatra have killed hundreds of thousands of people. Then, in 2005, Nias Island was rocked by an earthquake and killed more than 1000 people [4]. In addition, in 2010, a series of natural disasters came and went in Indonesia, such as the Tsunami in Mentawai, floods, landslides in Wasior, and volcanic eruptions in Yogyakarta [5]. Each of these events has caused various substantial effects on the affected area [6].

Natural and artificial disasters have occurred at record highs worldwide. This incident is a high consideration for the nursing profession to develop a strategic plan to deal with the situation [7] because nurses have a central role in providing or providing care in disaster events [8].

As a major group of health-care workers, nurses must train and equip themselves with a series of competencies to deal with disasters to save lives and protect health victims [9]. In addition, Public Health Nurses (PHNs) will be one of the disciplines that must be actively involved in disaster management programs [10]. The PHNs involvement in disaster management must be equally considered in all phases of a disaster phase [11]. To be actively involved in these phases, they need basic knowledge and skills regarding disaster management [12], which will help them to work effectively when a disaster occurs [13].

Indonesia has, in recent years, changed its disaster management strategy. Therefore, the participation and responsibility of various intersectoral entities are crucial, including government agencies, non-governmental organizations, the community, and health service providers, especially nurses [14]. Sultan et al. stated that the International Council for Nurses had reminded all nurses to have adequate knowledge to respond effectively to disaster events [9]. Florence Nightingale has been shown her essential role as a nurse when treating victims of the Crimean war, 
which opens the world's eyes to how important the responsibility of health-care workers is [9].

This literature study explores the PHNs' knowledge and perceived skills in the preparedness phase of disaster management. The specific goals of the study are to examine disaster management guidelines at the preparedness stage and describe the PHNs' knowledge and perceived skills in the preparedness phase.

When a disaster occurs, nurses must provide physical, psychological, and holistic care to individuals and community groups by prioritizing vulnerable groups, including pregnant women, children, and elder people [15]. Therefore, the knowledge and perceived skills for PHNs in disaster management are discussed in the preparedness phase. With the development of disaster management guidelines and practices among $\mathrm{PHNs}$ in Indonesia, it is hoped that it will provide appropriate direction for $\mathrm{PHNs}$ and significantly reduce the impact of disasters across the country.

\section{Materials and Methods}

This study uses a systematic review approach. Sources of data in this study derived from the literature obtained through various methods: Direct literature study, as well as using the internet to search for research results from local, national, and international online libraries. In this study, references based on inclusion criteria were included: Articles in English (primary) and Indonesian (addition) for research papers, guidelines/ standards from organizations, and books or e-book that relevant to disaster management in the nursing view from the community and clinical areas. In addition, the review articles answered the research question: Are there guidelines for disaster nursing or disaster management in place? The exclusion criteria were articles inconsistent with the research question and published over the past 20 years.

\footnotetext{
Studies derived from searches using search engines: Pubmed, Mendeley, GARUDA, G-Scholar, G-Web $(n=67)$

18 articles were excluded because they did not fit the query

12 items were excluded due to the year they were published in the last 20 years.

37 research papers/reviews/books/other reports are included in the inclusion criteria and then used as a reference for writing this review that derived from:

Elsevier $(n=7)$; Wiley $(n=7)$; Sagepub $(n=2)$; PLoS

Medicine $(n=1)$; BMC $(n=1)$; Springer $(n=2)$; Wolters

Kluwer $(n=1)$; Pearson Prentice Hall $(n=1)$; and

Others Publisher $(n=15)$
}

Figure 1: Searching methods

Various methods were applied to search reviews, articles, and other comprehensive reports from
Table 1: Characteristic references

\begin{tabular}{lll}
\hline Type of article & Date of publication & Methods \\
\hline Research article $(n=15)$ & $2002-2007(n=16)$ & Research article: \\
Review article $(n=13)$ & $2008-2013(n=11)$ & - Descriptive Study: Survey, \\
Guidelines $(n=4)$ & $2014-2020(n=10)$ & correlative, and comparative \\
Book/eBook $(n=4)$ & & - Mixed methods \\
Online newspaper $(n=1)$ & & - 3-round Delphi approach \\
& & - Qualitative \\
& - Pilot study \\
& Review article: \\
& & - Review research \\
& & - Review the theoretical and policy \\
& & - Review document of law and act \\
& & - Educational standards for \\
& & disaster care \\
\hline
\end{tabular}

conventional nursing and health databases. Databases were used (Figure 1) from 2002 until 2020. In addition, universal entry websites of cases such as Google-web and Google-scholar were utilized. Articles that meet the requirements or criteria (e.g., at Elsevier publishers) are systematically selected.

One researcher carried out the literature search seven times, beginning on April 1-September 30,2021 . Several keywords were used to obtain these papers, including disaster management, preparedness phases, the role of nurses/PHNs, disaster nursing, and $\mathrm{PHN}$. After passing through a systematic search above, 37 references were chosen for this writing. Details are described in Table 1.

\section{Discussion}

\section{Disaster management guidelines}

Nowadays, the incidence and frequency of disasters have been increasing as they occur approximately every 2 months in some areas worldwide [16]. As a result of environmental degradation, global climate change also generates a new problem related to weather pattern disturbance and its consequences in the future, particularly threatening human health [17]. The engagement of the nursing profession in disaster management aims to provide utmost care within limited resources and equipment in chaotic situations [18].

Conversely, many nurses acknowledged themselves as less appointed to work and act in important legislation, policy systems, and regulations that can improve and sustain the practice in any situation [19]. These conditions make them often feel inadequately prepared and integrated with National Disaster Policy and Response Teams to accomplish their crucial role in disaster prevention, response, and recovery [13]. Consequently, their contribution to the national action plan to enhance their knowledge and practices concerning disaster management is limited.

To deal with these circumstances, a guidance document on disaster management is needed to 
AQ4 Table 2: Summary of disaster management guidance at the preparedness stage

\begin{tabular}{|c|c|c|c|}
\hline Population & A phase of disaster management & Competencies in each phase & Author, country \\
\hline $\begin{array}{l}\text { All components of health } \\
\text { sectors, including the public } \\
\text { health system, PHNs, and } \\
\text { communities }\end{array}$ & $\begin{array}{l}\text { Preparedness: } \\
\text { Aims to develop decision making } \\
\text { in preparing for disaster event } \\
\text { that will include planning, training/ } \\
\text { education, resource management, } \\
\text { and exercising }\end{array}$ & $\begin{array}{l}\text { Preparedness } \\
\text { 1. Identify and develop the disaster plan among health-care providers } \\
\text { 2. Conduct a training and education program to provide the appropriate knowledge and } \\
\text { skill to implement the plans } \\
\text { 3. Identify resources such as plans, equipment, and staff to respond to the disaster } \\
\text { 4. Practice the present knowledge and skill into a practice scenario or disaster drill }\end{array}$ & [23], Canada \\
\hline Health sectors & $\begin{array}{l}\text { Warning } \\
\text { It aims to deliver an adequate warning } \\
\text { to the community regarding disaster } \\
\text { events }\end{array}$ & $\begin{array}{l}\text { Warning } \\
\text { 1. Inform the community regarding disaster event } \\
\text { 2. Identify source, content, and mechanism for warning if a disaster occurs }\end{array}$ & [24], Sri Lanka \\
\hline $\begin{array}{l}\text { Occupational and environmental } \\
\text { health professionals' including } \\
\text { nurse }\end{array}$ & $\begin{array}{l}\text { Pre-event } \\
\text { Pre-event refers to being well } \\
\text { prepared for public health care to face } \\
\text { the disaster event } \\
\text { Post-event (recovery) }\end{array}$ & $\begin{array}{l}\text { Pre-event } \\
\text { 1. Establish a disaster preparedness and response committee } \\
\text { 2. Develop a chain of command for communication, decision making, and reporting } \\
\text { 3. Define the potential work area, resources, or equipment for emergencies } \\
\text { 4. Disseminate the developing disaster plan } \\
\text { 5. Develop evacuation plans for normal and vulnerable populations } \\
\text { 6. Identify the risk of hazards or disaster } \\
\text { 7. Set procedures and teach staff how to report an emergency } \\
\text { 8. Plan for a backup system for any vital document and record } \\
\text { 9. Perform disaster exercises at least yearly }\end{array}$ & [1], USA \\
\hline Community/PHN (C/PHNs) & $\begin{array}{l}\text { Phase I (Pre-disaster) } \\
\text { Assessment, planning, and } \\
\text { implementation as the primary roles of } \\
\text { C/PHNs in this phase }\end{array}$ & $\begin{array}{l}\text { Phase I (Pre-disaster) } \\
\text { 1. Assess the potential resources and risks in a work setting } \\
\text { 2. Plans for disaster action included appropriately allocated resources, defining the roles } \\
\text { of C/PHNs in a disaster event, developing cooperative agreements with community } \\
\text { agencies, developing or activating disaster assessment tools/plans, developing } \\
\text { training/educational programs, and training the volunteer disaster nursing opportunities } \\
\text { 3. Practice the developed disaster plan }\end{array}$ & [20], USA \\
\hline
\end{tabular}

enable PHNs to enhance their knowledge and skills in emergency and disaster preparedness to competently manage disasters [12]. However, according to the Jennings-Sanders [20], the nursing guideline and standard of care on disaster management was still rare due to a lack of direction for nurses. Many organizations and experts have developed guidelines and a nursing disaster management model. These resources are valuable to health-care providers, especially nurses, who can guide and assist them in disaster preparedness, response, and recovery [21], [22]. The details of each guideline are discussed in Table 2.

\section{PHNs' knowledge and perceived skills in preparedness phase}

According to the Institute of Medicine, community (C/PHNs) have a responsibility to support the mission of the public health system to maintain and improve the community or population in healthy condition [21]. With this regard, PHNs should deliver health-care services and help individuals and communities equally regardless of individual economic and social status [11]. An Indonesian health development goal is to achieve a healthy life for every citizen to achieve optimal community health status. Therefore, the Indonesian Ministry of Health proposes the Public Health Center system, namely, Puskesmas, to accomplish this mission [25]. Initially, Puskesmas is the technical implementation unit of the public health district that is responsible for organizing health development in a working area [26].

A basic understanding of disaster science and the critical components of disaster management are crucial for nurses [27], particularly in preparing themselves for disaster preparedness [3]. The quality of disaster management also depends on staff's practice
[28]. Regular practice was found to enhance the knowledge and attributes to modify the attitude of healthcare providers [9]. Moreover, practice improves the knowledge and psychomotor skills that influence nurses' competency in making decisions [29], particularly when facing an uncommon situation like a disaster.

The criteria used to determine PHNs' knowledge and perceived skills in this study will consist of the core competencies derived from the fourth disaster management guidelines proposed that are described in Table 2. Although the competencies related to disaster management were not described thoroughly, the essential knowledge and perceived skills for successful disaster management were clearly illustrated in each process of disaster phase. Moreover, other evidence (Table 3) was used to support the specific skills in disaster management for PHNs, included PHNs' roles in the disaster preparedness phase.

In preparedness, PHNs should focus on personal preparation, such as understanding key terms, concepts, and roles in disaster preparation, including disaster plan and communication equipment used during disaster situations [10]. Furthermore, they should identify the types of disaster events that possible attack in their area [28] and assume the vulnerable population threatened by disaster events [22]. From this, core competencies in preparedness and risk reduction required by $\mathrm{PHNs}$ include demonstrating the ability to perform: Capacity assessment, planning and implementing prevention and mitigation activities, and planning and implementing emergency preparedness at the community and health facilities level [30]. Furthermore, to improve the present and updated knowledge regarding $\mathrm{PHNs}$ roles in disaster preparedness, regular educational training and workshop or simulation exercises or disaster drill will be required to support them further to be qualified staff 
Table 3: Included studies

\begin{tabular}{|c|c|c|c|c|}
\hline Authors, country & Methods & Participants & Context/Objective & Outcomes \\
\hline [30], South Africa & $\begin{array}{l}\text { Mixed methods } \\
\text { approaches }\end{array}$ & $\begin{array}{l}\mathrm{n}=6 \text { schools public health of } \\
\text { African universities, emergency } \\
\text { PHP from Ministries of Health, the } \\
\text { US CDC and prevention, and the } \\
\text { three levels of the WHO }\end{array}$ & $\begin{array}{l}\text { African health-care workers should possess skills } \\
\text { and knowledge to effectively participate in health } \\
\text { DRM activities. Three levels of training courses } \\
\text { are proposed: Basic, intermediate, and advanced. } \\
\text { The pilot test of the basic course among a cohort } \\
\text { of PHP in South Africa was also demonstrated }\end{array}$ & $\begin{array}{l}\text { Fourteen core competencies and } 45 \text { sub-competencies/ } \\
\text { training units grouped into six thematic areas: (1) } \\
\text { Introduction to DRM; (2) operational effectiveness; (3) } \\
\text { effective leadership; (4) preparedness and risk reduction; } \\
\text { (5) emergency response, and (6) post-disaster health } \\
\text { system recovery }\end{array}$ \\
\hline [9], Saudi Arabia & $\begin{array}{l}\text { Non-experimental } \\
\text { explorative design }\end{array}$ & $\begin{array}{l}\mathrm{n}=200 \text { registered nurses at the } \\
\text { emergency department with fluent } \\
\text { English and Arabic language }\end{array}$ & $\begin{array}{l}\text { Knowledge on disaster readiness, the role of the } \\
\text { emergency nurses on disaster response, and the } \\
\text { correlation of demographic variables with the level } \\
\text { of preparedness among the emergency nurses at } \\
\text { Ministry of health hospitals }\end{array}$ & $\begin{array}{l}\text { A majority of nurses provided sufficient knowledge } \\
\text { about disaster preparedness. Most emergency nurses } \\
(55 \%) \text { were moderately knowledgeable, and } 33 \% \text { were } \\
\text { adequately knowledgeable about disaster preparedness }\end{array}$ \\
\hline [15], Indonesia & $\begin{array}{l}\text { Sequential } \\
\text { exploratory } \\
\text { mixed-method } \\
\text { study }\end{array}$ & $\begin{array}{l}\text { Qualitative study: } \\
\mathrm{n}=56 \text { participants: Nurses, } \\
\text { disaster survivors, hospitalized } \\
\text { patients, members of the Ulama } \\
\text { Consultative Assembly of Aceh, } \\
\text { and hospital policymakers } \\
\text { Quantitative study: } \\
\mathrm{n}=150 \text { nurses from three hospitals }\end{array}$ & $\begin{array}{l}\text { Develop a study protocol to assess the } \\
\text { effectiveness of the intervention program to } \\
\text { improve nurses' disaster response skills }\end{array}$ & $\begin{array}{l}\text { Intervention program with local wisdom approaches such } \\
\text { as religion, beliefs, culture, and customs to provide care } \\
\text { and support for disaster survivors for nurses } \\
\text { This finding is expected to value significantly nursing } \\
\text { practice and education, particularly in developing and } \\
\text { adopting a disaster nursing education program based } \\
\text { on Islam }\end{array}$ \\
\hline [35], Philippines & $\begin{array}{l}\text { Descriptive survey } \\
\text { study }\end{array}$ & $\begin{array}{l}n=250 \text { nurses in community, } \\
\text { hospital, school, clinic, or industrial }\end{array}$ & $\begin{array}{l}\text { Assess and develop an action plan to enhance the } \\
\text { role, preparedness, and management of nurses in } \\
\text { the event of a disaster } \\
\text { Identify nurses in various specialty areas to } \\
\text { immediately prioritize the needs of individuals in } \\
\text { the event of an unforeseen situation }\end{array}$ & $\begin{array}{l}\text { Variations in characteristic respondents affect } \\
\text { their assessment of their roles, preparedness, and } \\
\text { management during catastrophic events. Nurses } \\
\text { grouped according to demographic variables present } \\
\text { similarities and differences in their responses to } \\
\text { devastating situations. Young nurses may be aggressive, } \\
\text { but older nurses are decisive }\end{array}$ \\
\hline [10], USA & $\begin{array}{l}\text { 3-round Delphi } \\
\text { approach }\end{array}$ & $\begin{array}{l}\mathrm{n}=\mathrm{PHNs} \text {, and directors of nursing } \\
\text { from local health departments, } \\
\text { state nursing leaders, and national } \\
\text { nursing preparedness experts }\end{array}$ & $\begin{array}{l}\text { Reviewed and commented on } 49 \text { draft } \\
\text { competencies derived from existing documents }\end{array}$ & $\begin{array}{l}\text { Competencies in preparedness focus on personal } \\
\text { preparedness; comprehending disaster preparedness } \\
\text { terms, concepts, and roles; familiar with the health } \\
\text { department's disaster plan, communication equipment } \\
\text { suitable for disaster situations; and the role of the PHN } \\
\text { in a surge event }\end{array}$ \\
\hline
\end{tabular}

such as isolation, difficulty expressing their needs, and help-seeking [33], including suffering and death during a disaster. Hence, health-care workers should be qualified and knowledgeable in these areas, including resource mobilization and management, essential logistical management, and the application of personnel safety and security measures were considered essential elements of sound public health disaster risk management [30].

The difficulty in evacuating these minority vulnerable groups is also caused by their rejects of assistance or cooperation with the evacuation plan [34]. Olu et al. [30] described some of the skills required in this situation. PHNs should be able to demonstrate: The ability to determine, mobilize, and manage resources, the capability to employ logistics management; and, the capability to utilize measures of safety and protection. Thus, data from assessing vulnerable populations provide the opportunity to develop specific evacuation plans or public policy and plan for help and nursing actions that can reduce the potential effects of disasters [22].

\section{Inter-agency collaboration}

Since disaster affects people and the community, the disaster victims require assistance from many organizations [21]. Therefore, the collaboration between each organization and profession is needed to be planned [11]. Teamwork and communication are essential between emergency personnel from other disciplines to establish appropriate patient responses [21]. With this regard, PHNs should address 
the emergency response plan and strategy used to be ready for disaster.

Consequently, the collaboration between organizations and disciplines is assured during a chaotic environment with limited resources from disaster to maintain adequate assistance and health-care services for the community [18]. In this case, management skills enhance effective coordination and collaboration among public safety agencies by enabling interoperable emergency alerts and incident information across disparate systems [35].

From this, PHNs must demonstrate flexibility in the types of tasks and duties without going beyond their knowledge, skills, and authority. During the initial intervention phase, key challenges include communication and continuity of care across multiple partners with diverse backgrounds and objectives. Inspired by the experiences of Haiti and Aceh, this presentation aims to determine best practices in nursing in the event of a disaster and explore the ethical considerations that arise in such a challenging environment [36].

Another example is that a nurse who typically works in adult nursing could be assigned to a disaster shelter with larger children. In this case, an adequate assessment of the child's health condition may require determining whether another field staff has the specialized knowledge and expertise in child care [15]. In addition, they also need to give consultants using telephone calls or seeking other assistance related to the problem. Moreover, suppose they cannot manage the problem. In that case, they should be familiar with the protocol and have access to communicate with the hospital's medical services and arrange immediate transfer to the hospital [28].

PHNs need to generate detailed intercollaboration that consists of a list of all organizations and their role in the emergency response, their location, how to access them, and how to stay informed about revisions to plans. Here, PHNs must have managerial skills to perform their nursing functions in the event of a disaster [35].

Furthermore, they should arrange a regular meeting to inform and re-inform the responsibility of each agency and evaluate the plan for effective action [37]. All agencies should also commit to this affiliation to enhance effective communication and collaboration to limit the morbidity and mortality in disaster occurrences [22]. Importantly, PHNs should build trust and strong relationships with stakeholders and people in the community to improve their awareness and readiness for the future disasters [1].

\section{Conclusion}

As a disaster-prone country, Indonesia has been plagued by natural disasters over the past few decades, which caused a large number of victims. As the largest group of health workers and nurses, in particular, PHNs need to train and equip themselves with a series of competencies to deal with disasters to save lives and protect health victims. PHNs will be one of the disciplines that must be actively involved in disaster management programs. They must respond by prioritizing vulnerable groups by providing physical, psychological, and holistic care to individuals and community groups. To overcome this condition, a guidance document on disaster management is required for $\mathrm{PHNs}$ to enhance their knowledge and skills in crisis and disaster preparedness to manage disasters competently. The regular practice was found to enhance the knowledge and attributes to modify the attitude of health-care providers, especially for the PHNs.

\section{References}

1. Rogers B, Lawhorn E. Disaster preparedness AAOHN J. 2007;55(5):197-207; quiz 208-9. https://doi. org/10.1177/216507990705500506

PMid: 17526297

2. Ranse J, Hammad K, Ranse K. Future considerations for Australian nurses and their disaster educational preparedness: A discussion. Aust J Emerg Manag. 2013;28(4):49-53.

3. Veenema TG. Disaster Nursing and Emergency Preparedness. $4^{\text {th }}$ ed. New York: Springer Publishing Company; 2018.

4. Pratama AN. Aceh Earthquake and Tsunami Caused Grief in Indonesia. (In Indonesia). Kompas; 2018.

5. Rindrasih E. Tourist's perceived risk and image of the destinations prone to natural disasters: The case of Bali and Yogyakarta, Indonesia. J Hum. 2018;30(2):192-203.

6. Pascapurnama DN, Murakami A, Chagan-Yasutan H, Hattori T, Sasaki H, Egawa S. Integrated health education in disaster risk reduction: Lesson learned from disease outbreak following natural disasters in Indonesia. Int J Disaster Risk Reduc. 2018;29:94-102. https://doi.org/10.1016/j.ijdrr.2017.07.013

7. Coyle GA, Sapnas KG, Ward-Presson K. Dealing with disaster. Nurs Manag. 2007;38(7):24-9

8. Cole FL. The role of the nurse practitioner in disaster planning and response. Nurs Clin North Am. 2005;40(3):511-21. https:// doi.org/10.1016/j.cnur.2005.04.007 PMid:16111996

9. Sultan MA, Mary PE, Grad HS. Emergency nurses readiness for disaster response an explorative study. Am Res J Nurs. 2018;4(1):1-10

10. Polivka BJ, Stanley SA, Gordon D, Taulbee K, Kieffer G, McCorkle SM. Public health nursing competencies for public health surge events. Public Health Nurs. 2008;25(2):159-65. https://doi.org/10.1111/j.1525-1446.2008.00692.x PMid:18294184

11. Jakeway CC, LaRosa G, Cary A, Schoenfisch S. The role of public health nurses in emergency preparedness and response: A position paper of the association of state and territorial directors of nursing. Public Health Nurs. 2008;25(4):353-61. https://doi.org/10.1111/j.1525-1446.2008.00716.x PMid:18666941 
12. Fung OW, Loke AY, Lai CK. Disaster preparedness among Hong Kong nurses. J Adv Nurs. 2008;62(6):698-703. https://doi. org/10.1111/j.1365-2648.2008.04655.x PMid: 18503654

13. Fritsch $\mathrm{K}$, Zang $\mathrm{Y}$. The Asia Pacific emergency and disaster nursing network: Promoting the safety and resilience of communities. Southeast Asian J Trop Med Public Health. 2009;40:71-8.

14. Martono M, Satino S, Nursalam N, Efendi F, Bushy A. Indonesian nurses' perception of disaster management preparedness. Chin J Traumatol. 2019;22(1):41-6. https://doi.org/10.1016/j. cjtee.2018.09.002

PMid:30850325

15. Husna C, Kamil H, Yahya M, Tahlil T. An intervention program to improve nurses' competencies in disaster response: A mixedmethods study protocol. Belitung Nurs J. 2020;6(3):85-90. https://doi.org/10.33546/bnj.1081

16. Morgan OW, Sribanditmongkol $P$, Perera $C$, Sulasmi $Y$, van Alphen D, Sondorp E. Mass fatality management following the South Asian tsunami disaster: Case studies in Thailand, Indonesia, and Sri Lanka. PLoS Med. 2006;3(6):e195. https:// doi.org/10.1371/journal.pmed.0030195 PMid: 16737348

17. Schipper L, Pelling M. Disaster risk, climate change and international development: Scope for, and challenges to, integration. Disasters. 2006;30(1):19-38.

18. O'Boyle C, Robertson C, Secor-Turner M. Public health emergencies: Nurses' recommendations for effective actions. AAOHN J. 2006;54(8):347-53. https://doi. org/10.1177/216507990605400802 PMid:16921865

19. Boatright $\mathrm{C}$, McGlown KJ. Homeland security challenges in nursing practice. Nurs Clin North Am. 2005;40(3):481-97. https://doi.org/10.1016/j.cnur.2005.04.003 PMid:16111994

20. Jennings-Sanders A. Teaching disaster nursing by utilizing the Jennings disaster nursing management model. Nurse Educ Pract. 2004;4(1):69-76. https://doi.org/10.1016/ S1471-5953(03)00007-6

PMid:19038139

21. Kuntz SW, Frable P, Qureshi K, Strong LL. Association of community health nursing educators: Disaster preparedness white paper for community/public health nursing educators. Public Health Nurs. 2008;25(4):362-9. https://doi. org/10.1111/j.1525-1446.2008.00717.x

PMid:18666942

22. Vogt $\mathrm{V}$, Kulbok PA. Care of Client in Disaster Settings Community Health Nursing: Advocacy for Population Health. $5^{\text {th }}$ ed. New Jersey: Pearson Prentice Hall; 2008. p. 759-800.

23. Manitoba Health. Disaster Management for the Health Sector, Guideline for Program Development Manitoba Health Disaster Management; 2002. Available from: https://terrorvictimresponse. ca/wp-content/uploads/2013/10/model.pdf [Last accessed on 2021 Aug 30].

24. World Health Organization. Guidelines on Disaster Management. A Compilation of Expert Guidelines on Providing Healthcare. Sri Lanka: World Health Organization; 2005.
25. Syukron A, Hasan N. Design of web-based outpatient information system at Puskesmas Winong. Bianglala Inform. 2015;3(1):28-34.

26. Adi IR, Laksmono BS. Analysis of the influence of organizationa factors and individual factors on the quality of health care services study at Puskesmas Kedawung District, Sragen Regency, Central Java Province. J IImu Kesejahteraan Sosial. 2018;18(1):34-47.

27. Halpern JS, Chaffee MW. Disaster management and response. Nurs Clin North Am. 2005;40(3):13-4

28. Qureshi K, Gebbie KM. Disaster management. In: Veenema, editor Disaster Nursing and Emergency Preparedness for Chemical, Biological, and Radiological Terrorism and other Hazard. $2^{\text {nd }}$ ed. New York: Springer Publishing Company; 2007. p. 137-60.

29. Arbon P. Understanding experience in nursing. J Clin Nurs. 2004;13(2):150-7. https://doi. org/10.1046/j.1365-2702.2003.00861.x PMid: 14723666

30. Olu O, Usman A, Kalambay K, Anyangwe S, Voyi K, Orach CG, et al. What should the African health workforce know about disasters? Proposed competencies for strengthening public health disaster risk management education in Africa. BMC Med Educ. 2018;18(1):1-10.

31. Stanley SA, Polivka BJ, Gordon D, Taulbee K, Kieffer G, McCorkle SM. The exploresurge trail guide and hiking workshop: Discipline-specific education for public health nurses. Public Health Nurs. 2008;25(2):166-75. https://doi. org/10.1111/j.1525-1446.2008.00693.x PMid: 18294185

32. Dyer CB, Regev M, Burnett J, Festa N, Cloyd B. SWiFT: A rapid triage tool for vulnerable older adults in disaster situations. Disaster Med Public Health Prep. 2008;2(S1):S45-50. https:// doi.org/10.1097/DMP.0b013e3181647b81 PMid: 18769267

33. Rothman M, Brown L. The vulnerable geriatric casualty: Medical needs of frail older adults during disasters. Generations. 2007;31(4):16-20.

34. Eisenman DP, Cordasco KM, Asch S, Golden JF, Glik D. Disaster planning and risk communication with vulnerable communities: Lessons from Hurricane Katrina. Am J Public Health. 2007;97 Suppl 1:S109-15. https://doi.org/10.2105/ AJPH.2005.084335

PMid: 17413069

35. Magnaye B, Munoz MS, Munoz MA, Munoz RG, Muro JH. The role, preparedness and management of nurses during disasters. E-Int Sci Res J. 2011;3(4):294.

36. Hynes GT. (A45) When nothing is left standing: Nursling's integral role during disaster response in Indonesia and Haiti. Prehosp Disaster Med. 2011;26(S1):S13.

37. Stanley J, Chastain CA, Davies RK, Deeny PP, Etherington C, Gebbie FK, et al. Educational Competencies for Registered Nurses Responding to Mass Casualty Incidents Report Prepared for the International Nursing Coalition for Mass Casualty Education By INCMCE Competency Committee. Vol. 40. Nursing Clinics of North America; 2003 p. 453-67. Available from: https://linkinghub.elsevier.com/retrieve/pii/ S0029646505000253 [Last accessed on 2021 Sep 15]. 